\section{Fgf-10 is required for both limb and lung development and exhibits striking functional similarity to Drosophila branchless}

\author{
Hosung Min, ${ }^{1}$ Dimitry M. Danilenko, ${ }^{2}$ \\ Sheila A. Scully, ${ }^{2}$ Brad Bolon, ${ }^{2}$ Brian D. Ring, ${ }^{2}$ \\ John E. Tarpley, ${ }^{2}$ Margaret DeRose, ${ }^{1}$ \\ and W. Scott Simonet ${ }^{1,3}$
} Departments of ${ }^{1}$ Molecular Genetics and ${ }^{2}$ Pathology, Amgen,
Inc., Thousand Oaks, California 91320-1789 USA

Fgf-10-deficient mice $\left(\mathrm{Fgf-10}^{-/-}\right)$were generated to determine the role(s) of $F g f-10$ in vertebrate development. Limb bud initiation was abolished in $\mathrm{Fgf-10}^{-/-}$mice. Strikingly, $\mathrm{Fg}-\mathrm{HO}^{-/-}$fetuses continued to develop until birth, despite the complete absence of both fore- and hindlimbs. Fgf-10 is necessary for apical ectodermal ridge (AER) formation and acts epistatically upstream of $F g f-8$, the earliest known AER marker in mice. Fgf-10 ${ }^{-/-}$ mice exhibited perinatal lethality associated with complete absence of lungs. Although tracheal development was normal, main-stem bronchial formation, as well as all subsequent pulmonary branching morphogenesis, was completely disrupted. The pulmonary phenotype of Fgf- $10^{-/-}$mice is strikingly similar to that of the Drosophila mutant branchless, an Fgf homolog.

Received July 23, 1998; revised version accepted August 2, 1998.

Fibroblast growth factor (FGF) family members have been implicated in multiple aspects of vertebrate embryonic development and adult tissue homeostasis (for review, see McKeehan et al. 1998). During development, FGFs act as essential mediators of mesenchymal-epithelial interactions. Vertebrate limb bud formation is an excellent example of how such interactions regulate patterning in the developing embryo.

Initiation of limb buds in vertebrate embryos results from outward proliferation of the lateral plate mesoderm (for review, see Johnson and Tabin 1997). The distal ectoderm surrounding this region is then induced by dividing mesenchymal cells to thicken and form a structure called the apical ectodermal ridge (AER; Saunders 1948). Different but interacting signaling pathways specify the orientation of the expanding limb tissues in all three dimensions. Molecular interactions between the AER

[Key Words: Fgf-10; limbless; limb bud initiation; branchless; pulmonary branching morphogenesis]

${ }^{3}$ Corresponding author.

E-MAIL ssimonet@amgen.com; FAX (805) 447-1982. and the underlying mesenchyme are important for proximal-distal patterning. FGF-2, -4 , and -8 are expressed in chick AER and can replace the AER to induce underlying mesenchyme to maintain its distal outgrowth (for review, see Johnson and Tabin 1997; Martin 1998). Anterior-posterior patterning of each limb bud is dictated by the zone of polarizing activity (ZPA), located at the posterior margin of the limb bud mesenchyme (Saunders and Gasseling 1968). The secreted factor Sonic hedgehog ( $\mathrm{SHh}$ ) is believed to be responsible for the morphogenetic role of the ZPA (Riddle et al. 1993; Chang et al. 1994; Lopez-Martinez et al. 1995). Transcription factors and secreted proteins, including Engrailed-1 (En-1), Wnt-7a, and Lmx-1, play roles in dorsal-ventral specification of limbs (Parr and McMahon 1995; Riddle et al. 1995; Loomis et al. 1996).

Tissue graft experiments indicate that vertebrate limb bud formation is initiated by factors from mesoderm within the limb field (Saunders and Reuss 1974). Implantation of beads soaked in FGFs or FGF-expressing cells can induce formation of ectopic limbs in chick embryos. FGF-1, -2, -4, -8, and -10 exhibit limb-inducing activity (Cohn et al. 1995; Ohuchi et al. 1995; Crossley et al. 1996; Vogel et al. 1996; Ohuchi et al. 1997). However, only Fgf-8 and Fgf-10 exhibit the correct temporal and spatial expression that could direct limb bud initiation (Crossley et al. 1996; Vogel et al. 1996; Ohuchi et al. 1997). Fgf-8 in chick embryos is expressed in intermediate mesoderm at presumptive limb regions before limb bud initiation. In contrast, Fgf-10 is expressed in lateral plate mesoderm within the limb field prior to limb bud initiation, and the expression persists in the mesenchyme under AER after initial limb bud formation.

Interestingly, circumstantial evidence suggests that FGF-10 may also affect development of the vertebrate lung. In mice, lung morphogenesis begins with ventral extension of the laryngotracheal groove from the primitive gut endoderm at E9.5 (Kaufman 1992). Shortly thereafter, the tracheal primordium bifurcates to produce left and right principal (main-stem) bronchi, around which the lung buds will differentiate. Further branching morphogenesis results in development of the bronchioles and alveoli that form mature lung parenchyma. Recent reports suggest that an FGF-mediated signal transduction pathway plays an essential role in lung development. A splice variant of Fibroblast growth factor receptor 2 (Fgfr2b) is highly expressed in respiratory epithelium during early branching morphogenesis (OrrUrtreger et al. 1993). FGF-10, which binds to FGFR2b and is expressed in lung buds, is a good candidate for a molecule involved in lung branching morphogenesis (Bellusci et al. 1997; Igarashi et al. 1998).

To directly examine the physiological role(s) of FGF-10 during vertebrate development, we generated Fgf-10 knockout $\left(F g f-10^{-/-}\right)$mice. We show that FGF-10 is critical for both limb and lung development, revealing this factor as an important developmental mediator of patterning and organogenesis. 


\section{Results}

We have shown previously that overexpression of FGF-7 in mice using the human SP-C promotor results in severe pulmonary malformation (Simonet et al. 1995). Despite our results and other mounting evidence indicating that FGF-7 is a potential morphogen for embryonic lung development (Nogawa and Itoh 1995; Simonet et al. 1995; Post et al. 1996; Cardoso et al. 1997), Fgf-7 knockout mice failed to develop any lung defect (Guo et al. 1996). However, overexpression of a dominant-negative form of FGFR2b (a receptor for FGF-7) under control of the SP-C promotor resulted in a complete absence of lung tissue in mice (Peters et al. 1994). Thus, we sought other FGFs that might function as lung morphogens by binding to FGFR2b. A promising candidate is FGF-10, which among FGF family members is most homologous to FGF-7, binds FGFR2b with high affinity, and is highly expressed during lung branching morphogenesis (Yamasaki et al. 1996; Bellusci et al. 1997; Igarashi et al. 1998). Therefore, we examined the role of FGF-10 in mouse development by generating Fgf-10-deficient mice.

The strategy for targeted deletion of the endogenous mouse Fgf-10 gene is outlined in Figure 1 (A-C). The cDNA encoding Fgf-10 has been isolated from rat, human, and mouse (Yamasaki et al. 1996; Emoto et al. 1997; Tagashira et al. 1997). The nucleotide and deduced amino acid sequences are highly conserved $(90 \%+$ identity), and no alternative splicing of exons was observed in any species. Because exon 1 of Fgf-10 encodes the translation start site, putative signal peptide, and receptor specificity-conferring region of the mature protein, we sought to disrupt exon 1 of Fgf-10. Our strategy replaced a region of exon 1 containing the translation start site and the putative signal peptide with a PGK-neo cassette in reverse orientation (Fig. 1A,C). Southern blot genotype analysis of E17.5 fetuses revealed expected wildtype and mutated alleles of 4.3- and 1.4-kb EcoRI fragments, respectively (Fig. 1D). Northern blot analysis of total RNA from E11.5 embryos showed that Fgf-10 transcripts are absent in $\mathrm{Fgf-10^{-/- }}$ embryos (Fig. 1E).

Fgf-10 $10^{-/-}$mice exhibited perinatal lethality. Among pups born from heterozygote $\left(F g f-10^{+/-}\right)$matings, at least seven $\mathrm{Fg} f-10^{-/-}$newborn pups were found dead in cages (data not shown). Analysis of 108 surviving mice at weaning age showed only $\mathrm{Fgf}-10^{+/-}(65 \%)$ or $\mathrm{Fgf}-1 \mathrm{O}^{+/+}$ $(35 \%)$ mice. Analysis of 134 conceptuses ranging from E9.5 to E17.5 showed percentages of 26, 51, and 23 for $+/+,+/-$, and $-/-$, respectively. This is close to the expected Mendelian ratio of $1: 2: 1$, suggesting that $F g f-10^{-/-}$ mice are surviving gestation but die immediately after birth.

Gross examination of Fgf-10-1- embryos revealed complete absence of budding limbs at E9.5 (Fig. 2A) and E10.5 (data not shown). Consistent with the phenotype of these earlier embryos, E17.5 fetuses lacked both foreand hindlimbs (Fig. 2B). Crown-rump lengths of E17.5 Fgf- $10^{-1-}$ fetuses were, on average, $2.0 \mathrm{~mm}(12 \%)$ shorter than their wild-type and heterozygote littermates. All other external structures of $\mathrm{Fg} f-10^{-/-}$fetuses were nor-
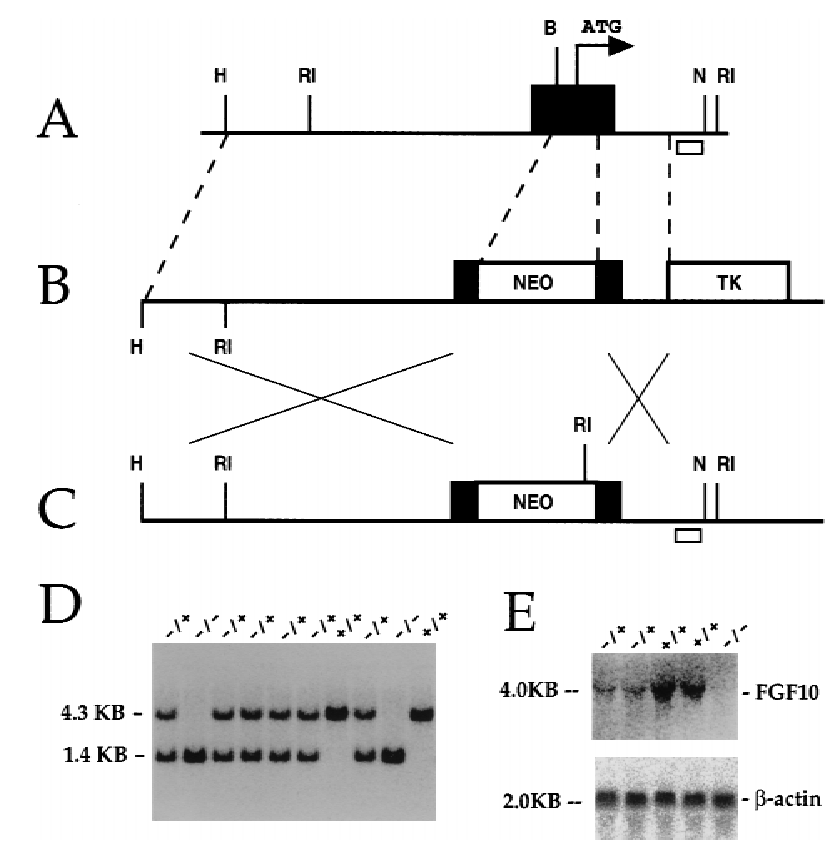

Figure 1. Targeted disruption of the murine Fgf-10 gene. (A) Schematic diagram of the Fgf-10 exon 1 (black box) locus in mice. The translation initiation site (ATG) is indicated by a bent arrow. Restriction sites are indicated as follows: $(\mathrm{H})$ HindIII; (RI) EcoRI; (B) BamHI; and (N) NotI. (B) The targeting vector. The $3.5-\mathrm{kb}$ long arm of homology and the $0.78-\mathrm{kb}$ short arm of homology are placed flanking the PGK-neo casette, which is in reverse orientation. The PGK-tk cassette is adjacent to the short arm. This strategy eliminates the translation initiation codon (ATG) and the predicted signal peptide and places multiple stop codons in-frame. $(C)$ The resulting targeted allele after homologous recombination. (D) Genomic Southern blot using EcoRI-digested DNA. The wild-type allele is a $4.3-\mathrm{kb}$ fragment, whereas the targeted allele is a $1.4-\mathrm{kb}$ fragment. The heterozygote mice (+/ -$)$ have both alleles. The small open box in $A$ and $C$ represents DNA probe used for Southern blot experiments. $(E)$ Northern blot analysis of RNA from embryos (E11.5) derived from heterozygous matings. Only wild-type and heterozygote embryos show the $4.0-\mathrm{kb}$ transcript. The same blot is probed with $\beta$-actin as an endogenous control for RNA loading.

mal. These results demonstrate conclusively that FGF10 is necessary for limb bud initiation. Although Fgf-10 transcript levels in $\mathrm{Fgf-10^{+/- }}$ embryos were lower compared to the levels in $F g f-10^{+/+}$embryos (Fig. 1E), the heterozygote embryos developed normally.

Bone structure in E18.5 Fgf-10 ${ }^{-/}$fetuses was examined by skeletal double staining (Fig. 2C-H). The shoulder region contained a scapula but exhibited no forelimb development (Fig. 2C,D,F,G). Similarly, the pelvic region contained only a rudimentary cartilaginous pelvic girdle with no evidence of hindlimb growth (Fig. 2E,H), indicating that limb formation was completely abolished by Fgf-10 deficiency.

Fgf-10 expression in chick lateral plate mesoderm (LPM) precedes FGF-8 expression in the presumptive limb ectoderm (Ohuchi et al. 1997). Expression of Fgfr2b is detected in the developing limb epithelium and colocalized with Fgf-8 expression in AER of wild-type mouse 

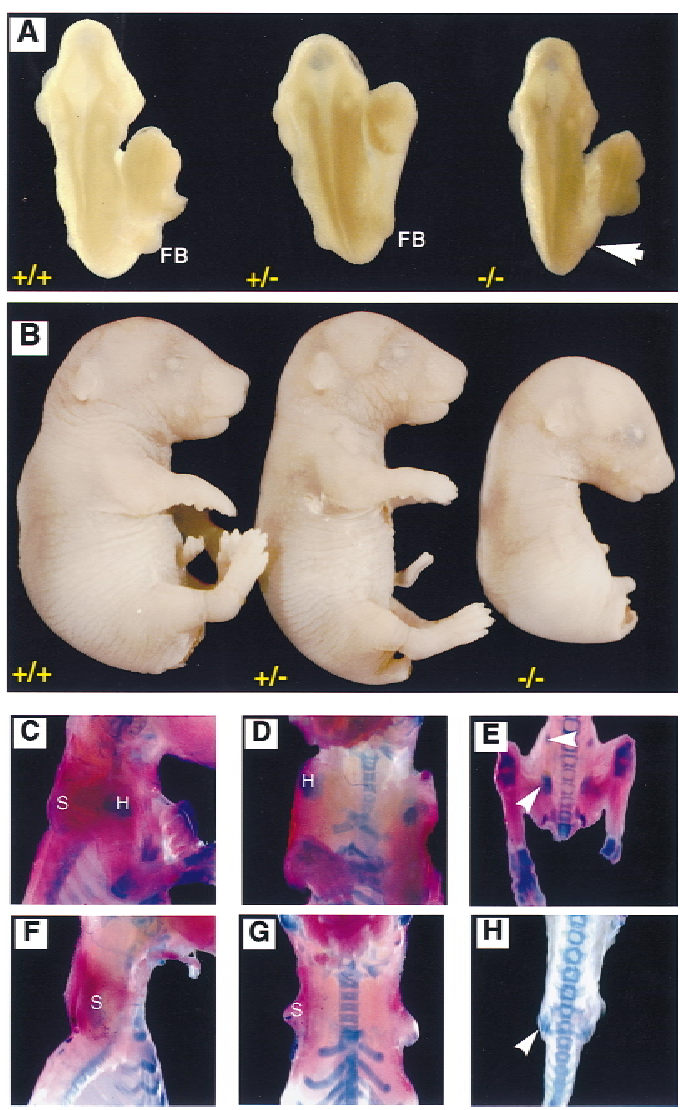

Figure 2. Gross morphology and bone structure of $\mathrm{Fgf-10^{-/ } -}$ mice. Gross photographs of E9.5 $(\mathrm{A})$ and E17.5 $(\mathrm{B}) \mathrm{Fgf-10^{-/- }}$ conceptuses are shown with $\mathrm{Fgf}-1 \mathrm{O}^{+/-}$and $\mathrm{Fgf}-10^{+/+}$littermates for comparison. $(A$, dorsal view) A complete absence of forelimb buds (arrow) in the Fgf-10 ${ }^{-/-}$embryo relative to the presence of a forelimb bud (FB) in Fgf-10 ${ }^{+/+}$and $\mathrm{Fgf}-10^{+/-}$littermates; $(B$, lateral view) complete absence of both limbs in the Fgf-10-/ near-term fetus; $(C-H)$ Gross photographs of E18.5 term Fgf$10^{-/-}(F-H)$ and wild-type $(C-E)$ fetuses that have undergone skeletal double staining. Both wild-type $(C-E)$ and $F g f-10^{-/-}(F-$ $H)$ fetuses have scapulas with a blue-stained cartilaginous cap (S in $C, D, F$, and $G$ ) and pelvic girdles (arrowheads in $E$ and $H$ ). However, the $\mathrm{Fgf-10^{-/- }}$ pelvic girdle is rudimentary and entirely cartilaginous (blue stained), whereas the wild-type pelvic girdle contains both bone (arrowhead directed at red-stained area) and cartilage (arrowhead directed at blue-stained area). The head of the humerus (blue-stained area labeled $H$ ) is visible only in the wild-type fetus $(C, D)$ and obscures the scapula in the ventral view $(D)$.

limb buds at E9.5 (Fig. 3C,D). Fgf-10 expression was observed in the corresponding underlying mesenchyme (Fig. 3B). Expectedly, no Fgf-10 expression was observed in Fgf-10 $10^{-/}$embryos, although Fgfr2b was expressed in the presumptive limb regions of $F g f-10^{-/-}$embryos (data not shown). Fgf-8 expression was analyzed to determine whether endogenous Fgf-10 expression in murine LPM is required for $F g f-8$ expression in AER. No Fgf-8 expression was observed in presumptive limb ectoderm of E9.5 Fgf$10^{-/-}$embryos (Fig. $3 \mathrm{H}$ ), whereas strong Fgf-8 expression was observed in the emerging AER of wild-type embryos (Fig. 3D,F). We conclude that Fgf-10 expression in mu- rine LPM is both necessary for and acts epistatically upstream of Fgf-8 expression in AER.

In contrast to other mouse mutants that lack limb buds (Chiang et al. 1996; Sanford et al. 1997; Xu et al. 1998), Fgf-10 $10^{-/}$mice, with the exception of being slightly smaller, exhibit normal external development through gestation (up to E18.5). However, histological examination of near-term fetuses on E17.5 revealed that

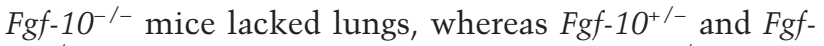
$10^{+/+}$fetuses had normal lungs (Fig. 4). Fgf-10 $10^{-/-}$fetuses showed normal tracheal development, including cartilage around the tracheal walls, ciliated pseudostratified columnar mucosal epithelium, and mucus-secreting

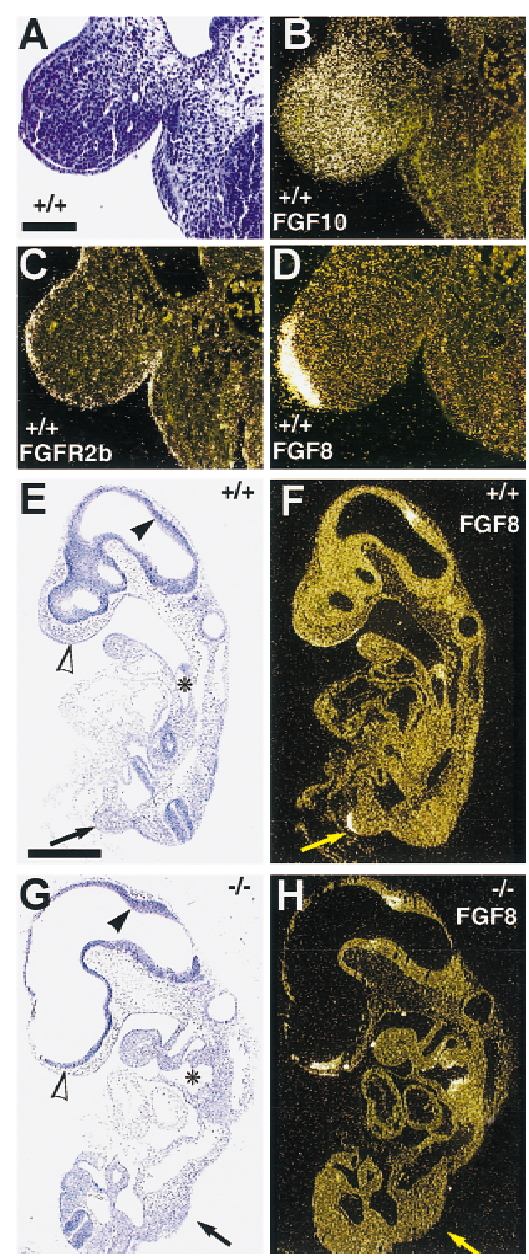

Figure 3. In situ hybridization of the nascent forelimb bud in E9.5 mouse embryos. $(A-D)$ Limb bud of wild-type embryo (bar, $500 \mu \mathrm{m})$. Diffuse Fgf-10 expression occurs in limb bud mesenchyme $(B)$. Fgfr2b is expressed throughout the epithelium in the developing limb region $(C)$, whereas $F g f-8$ is specifically expressed in AER $(D) .(E-H)$ Distribution of Fgf-8 mRNA in Fgf$10^{+/+}(E, F)$ and $F g f-10^{-/-}(G, H)$ embryos (bar, $\left.100 \mu \mathrm{m}\right)$. Note the absence of an Fgf-8 signal near the presumptive site of limb bud initiation (arrow) in the Fgf-10-1- embryo. Fgf-8 expression in

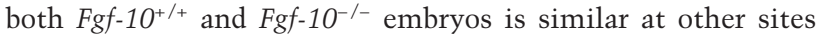
including the neuroectoderm of the rostral telencephalon (open arrowhead), the junction of the mesencephalon and rhombencephalon (arrowhead), and the pharyngeal epithelium $\left({ }^{\star}\right)$. $(A, E, G)$ Stained with eosin plus hematoxylin in $A$. 
goblet cells (Fig. 4A-C), indicating that FGF-10 is not necessary for initial extension of the laryngotracheal groove from the primitive gut endoderm. However, the trachea of $\mathrm{Fgf-10^{-/- }}$ fetuses terminated at the level of the thymus. No main-stem bronchi or subsequent pulmonary bronchiolar and alveolar development occurs (Fig. 4D-I). These results indicate that FGF-10 is required for initial branching of the primordial bronchi during the early phase of embryonic lung development.

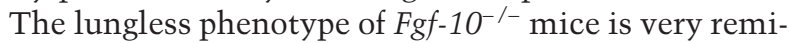
niscent of the Drosophila mutant branchless (bnl), an Fgf homolog. In bnl mutants, initial budding of tracheal cells occurs, but further branching is impaired (Sutherland et al. 1996). A 99-amino-acid stretch of bnl is 30\%$40 \%$ identical to several vertebrate $F g f$ s (Sutherland et al. 1996). Analysis of sequence homology between Drosophila bnl and mouse Fgfs that are expressed during lung development, namely Fgf-1, Fgf-7, and Fgf-10 (Fu et al. 1991; Mason et al. 1994; Bellusci et al. 1997), failed to identify any single murine homolog of bnl. Fgf-1, Fgf-7, and $\mathrm{Fgf}-10$ show $35 \%, 33 \%$, and $37 \%$ sequence identities, respectively, to bnl in the 99-amino-acid stretch. Thus, the percent identities within the core regions of these murine Fgfs are similar. However, Fgf-10 in mice and bnl in Drosophila bear striking functional similarity
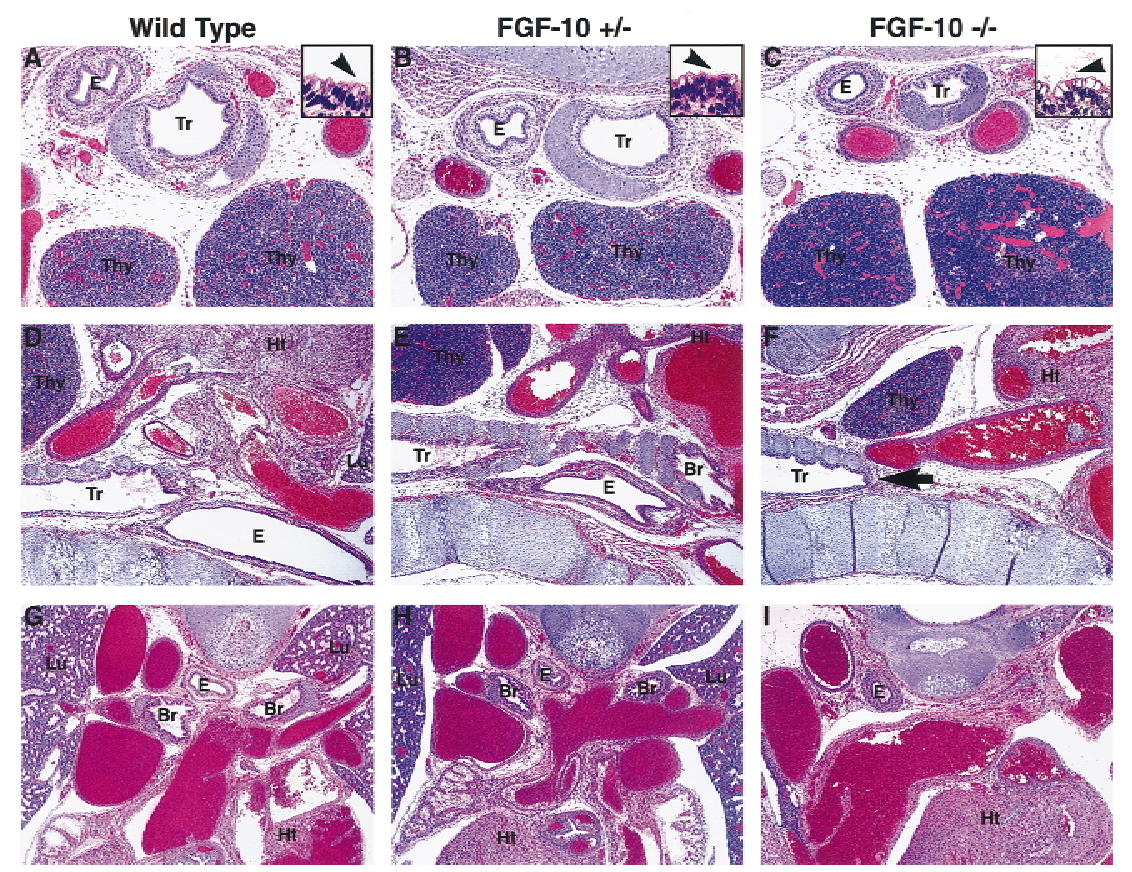

Figure 4. H\&E-stained sections of E17.5 $\mathrm{Fgf}-10^{-/-}$fetuses $(C, F, I)$ with $\mathrm{Fg} f-10^{+/+}$ $(A, D, G)$ and $F g f-10^{+/-}(B, E, H)$ littermates for comparison. $(A-C)$ Fetal cross sections showing that $\mathrm{Fgf-10^{-/- }}$ fetuses have a normal trachea (Tr) and thymus (Thy). (Insets in $A-C)$ The tracheal epithelium from $F g f-10^{-/-}$fetuses is ciliated pseudostratified columnar (inset arrowheads indicate cilia) with mucus-secreting goblet cells (clear areas) and is morphologically identical to tracheal epithelium in wild-type and heterozygous fetuses. $(D-F)$ Fetal sagittal sections showing that the $F g f-10^{-/-}$fetal trachea terminates blindly just beyond the anterior thymus (arrow in $F$ ), whereas the tracheas in wild-type and heterozygous fetuses continue beyond the thymus and branch to form main-stem bronchi $(E)$. $(G-I)$ Fetal cross sections showing that $F g f-10^{-/-}$fetuses $(I)$ fail to develop main-stem bronchi $(\mathrm{Br})$ or lungs $(\mathrm{Lu})$. (E) Esophagus; and $(\mathrm{Ht})$ heart in $A-I$. in that both are critical for initial pulmonary branching events.

\section{Discussion}

FGFs and their receptors are critical mediators of embryonic development and adult tissue homeostasis in vertesignaling through a common splice variant of FGFR2 is widely expressed in epithelial cells of developing animals. Nevertheless, the roles of these two embryo clearly are quite different. Fgf-7-deficient mice develop normally, indicating that either FGF-7 is not rement in its absence. Targeted deletion of many FGF fam members in mice have provided limited biological (necause of either embryonic lethality or redunIncy in FGF signaling pathways (MeKeehan et al. 1998). mice reported here reveals that FGF-10 is tely required for normal patterning and development during the early phases of limb bud initiation and pulmonary branching morphogenesis.

Expression of Fgf-8, one of the earliest AER markers associated with limb bud initiation (Crossley et al. 1996; Vogel et al. 1996), is completely abolished in presumptive limb ectoderm of $F g f-10^{-/-}$ embryos compared to that of wild-type littermates. Thus, Fgf-10 is required for induction of $F g f-8$ expression in AER and acts epistatically upstream of $F g f-8$ to regulate limb bud initiation. This result is consistent with expression patterns in chick embryos where Fgf-10 in lateral plate mesoderm precedes $F g f-8$ in AER (Ohuchi et al. 1997). Implantation studies using Fgf-8 and Fgf-10-expressing cells suggest that these factors might work in a reciprocal manner (Ohuchi et al. 1997). In this model, initial Fgf-10 expression in LPM induces Fgf-8 expression in AER, and Fgf- 8 in turn enhances Fgf-10 expression in the underlying mesenchyme. This hypothesis is reinforced by studies performed in mouse embryos carrying targeted deletions of the immunoglobin domain of Fgfr2. These embryos lacked limb buds and failed to form a functional placenta. They also exhibited no Fgf-8 expression in presumptive ectoderm and downregulation of Fgf-10 in underlying mesenchyme (Xu et al. 1998). FGF-10 has been shown to bind to FGFR2b (Igarashi et al. 1998). Our data, coupled with these observations, indicates that FGF10 expressed in murine LPM induces 
FGF-8 expression by activating FGFR2b in AER. The possibility exists that Fgf-8 expression is initiated in preAER cells but is not maintained in AER owing to lack of Fgf-10.

Both Fgf-8 and Fgf-10 are expressed in intermediate mesoderm (IM) prior to limb bud initiation, and both are proposed to be factors involved in limb field specification that emanate from this region (Crossley et al. 1996; Ohuchi et al. 1997). However, it remains controversial whether contributions from IM are necessary for limb bud formation (for review, see Johnson and Tabin 1997). Fgf-8 expression and limb initiation in chick IM have been proposed to be linked to embryonic kidney development (Crossley et al. 1996). However, it is not clear whether Fgf-10, which is expressed early in the segmental plate and IM, interacts with FGF-8. Our findings suggest that FGF-10 is not necessary for embryonic kidney development, as our E17.5 FGF-10-/- fetuses exhibited histologically normal kidneys (data not shown).

Fgf-8 expression in other regions of E9.5 Fgf-10-/- embryos apparently is normal. Fgf- 8 is expressed in several regions of the developing brain and in the pharyngeal epithelium of both $\mathrm{Fgf-10^{-/ }}$ embryos and their wild-type littermates (Fig. 3E-H). Therefore, Fgf-10-dependent expression of Fgf-8 appears to be confined to limb buds. Consistent with this finding, the $F g f-10^{-/-}$mice do not show defects in other organ systems, with the exception of lungs. Other mouse limb mutants exhibit either early embryonic lethality or severe gross morphologic defects (Chiang et al. 1996; Sanford et al. 1997; Xu et al. 1998).

Lack of lungs and main-stem bronchi in Fgf-10-/- mice is very reminiscent of the Drosophila mutant bnl. Both genetic and biochemical evidence indicates that $b n l$ is a ligand for breathless (btl), an Fgf receptor. Drosophila btl mutants exhibited a phenotype that was very similar to that of bnl (Sutherland et al. 1996). Mammalian Fgfr2b is highly expressed in the epithelium throughout embryonic lung development (Orr-Urtreger et al. 1993). Transgenic mice expressing a dominant-negative form of FGFR2b splice variant under control of the SP-C promotor exhibited perinatal lethality and failed to develop lungs, indicating that FGFR2b is a receptor necessary for pulmonary branching morphogenesis (Peters et al. 1994). Ligands of this receptor include FGF-1, FGF-7, and FGF10 (Ornitz et al. 1996; Igarashi et al. 1998), and all three have been shown to promote expansion and/or budding of endodermal cells in lung explant studies (Bellusci et al. 1997). Fgfr2b transgenic mice exhibited trachea formation and bifurcation of main-stem bronchi (Peters et al. 1994), unlike the Fgf-10 knockout mice, which only developed a trachea without further branching. This difference was most likely caused by spatial and temporal differences between Fgf-10 expression and SP-C promotor activity. The SP-C promotor drives transgene expression in distal lung epithelium starting at E10 /Wert et al. 1993). In contrast, Fgf-10 is already expressed in the distal mesenchymal cells of developing respiratory tract buds at E9.5 (Bellusci et al. 1997). Presumably, by E10E10.5, the formation of the primordial bronchi has already occurred. The impaired pulmonary development observed in Fgfr2b transgenic mice, coupled with similarities in pulmonary phenotypes of Fgf-10 knockout mice and Drosophila bnl and btl mutants, suggests striking functional similarities in the signaling pathways of mammalian Fgf-10 and Drosophila bnl.

\section{Materials and methods}

FGF-10 targeting strategy and generation of knockout mice A mouse genomic clone that contains Fgf-10 exon 1 was isolated by screening the 129 SVJ Lambda Fix II library (Stratagene, La Jolla, CA) with a radiolabeled probe containing a portion of the mouse $F g f-10 \mathrm{cDNA}$ (nucleotides -108 to +99 ). The targeting vector (Fig. 1B) was constructed by placing a 3.5 -kb-long arm of homology and 0.78 -kb short arm of homology flanking the PGK-neo casette. The PGK-tk cassette was placed next to the short arm. This targeting strategy replaces a 294-nucleotide region of Fgf-10 exon 1 containing the translation initiation site and putative signal peptide with the PGK-neo casette. About 10 million RW4 ES cells were electroporated with $25 \mu \mathrm{g}$ of the targeting vector. After Gancyclovir and G418 selection, 264 surviving colonies were isolated. Five colonies bearing the targeted allele were identified by both Southern blot and PCR analyses. Three of the five positive clones were injected into fertilized C57BL/ 6 blastocysts to produce chimeric males, and these males were crossed with either 129 SVJ or Swiss black females. Chimeras from all three clones exhibited germ-line transmission. Heterozygote males and females from each clone were crossed to obtain embryos at E9.5, E10.5, E11.5, E17.5, and E18.5.

Gross and histologic examinations and in situ hybridization Fgf-10 E9.5-E17.5 null conceptuses with wild-type and heterozygote littermates were harvested and fixed overnight in $10 \%$ neutral buffered zinc formalin (Anatech, Battle Creek, MI). The day on which a copulation plug was detected was designated gestational day 0 (E0). Fixed conceptuses were grossly examined and photographed. Fixed tissue blocks (E17.5 fetuses) or whole embryos were then dehydrated, paraffin embedded, and serially sectioned at $3 \mu \mathrm{m}$. Selected sections were stained with hematoxylin and eosin $(\mathrm{H} \& \mathrm{E})$ for routine histologic examination. All major organs, including brain, spinal cord, thymus, gastrointestinal tract, liver, lung, kidney, and skin were examined.

For in situ hybridization, formalin-fixed, paraffin-embedded sections of E9.5 embryos were hybridized with ${ }^{33} \mathrm{P}$-labeled transcripts synthesized from DNA templates derived from mouse Fgf-10, Fgf-8, and Fgfr2b cDNA sequences as described (Wilcox 1993). Slides were counterstained with $\mathrm{H} \& \mathrm{E}$ and photographed using dark-field illumination.

Skeletal double staining of embryos

E18.5 embryos were collected, skinned, eviscerated, and fixed for $24 \mathrm{hr}$ in $95 \%$ ethanol. Two modifications were made to a previously published double staining method (Miller and Tarpley 1996): (1) because only a few embryos were stained per run, the staining was not automated and agitation was provided by a shaker table; and (2) because mice were used rather than rats, the concentration of potassium hydroxide was lowered to $1 \%$. Briefly, the method consists of $24-\mathrm{hr}$ changes of alcian blue, potassium hydroxide, and murexide followed by clearing in glycerin. Photography was done using a Nikon SMZU dissecting microscope fitted with a digital camera (Sony DKC-5000).

\section{Acknowledgments}

We thank Nathan Bucay and John Shutter for advice on ES cell work, Laura Martin for blastocyst injections, Kathy Christensen for colony maintenance, and Diane Duryea for histology support. We also thank David Warburton, Chris Paszty, and members of Simonet laboratory for helpful and stimulating discussions.

The publication costs of this article were defrayed in part by payment of page charges. This article must therefore be hereby marked 'advertisement' in accordance with 18 USC section 1734 solely to indicate this fact.

\section{References}

Bellusci, S., J. Grindley, H. Emoto, N. Itoh, and B.L.M. Hogan. 1997. 
Fibroblast growth factor 10 (FGF10) and branching morphogenesis in the embryonic mouse lung. Development 124: 4867-4878.

Cardoso, W.V., A. Itoh, H. Nogawa, I. Mason, and J.S. Brody. 1997. FGF1 and FGF7 induce distinct patterns of growth and differentiation in embryonic lung epithelium. Dev. Dyn. 208: 398-405.

Chang, D.T., A. López, D.P. von Kessler, C. Chiang, B.K. Simandl, R. Zhao, M.F. Seldin, J.F. Fallon, and P.A. Beachy. 1994. Products, genetic linkage and limb patterning activity of a murine hedgehog gene. Development 120: 3339-3353.

Chiang, C., Y. Litingtung, E. Lee, K.E. Young, J.L. Cordoen, H. Westphal, and P.A. Beachy. 1996. Cyclopia and defective axial patterning in mice lacking Sonic hedgehog gene function. Nature 383: 407-413.

Cohn, M.J., J.-C. Izpiseúa-Belmonte, H. Abud, J.K. Heath, and C. Tickle. 1995. Fibroblast growth factors induce additional limb development from the flank of chick embryos. Cell 80: 739-746.

Crossley, P.H., G. Minowada, C.A. MacArthur, and G.R. Martin. 1996. Roles for FGF8 in the induction, initiation, and maintenance of chick limb development. Cell 84: 127-136.

Emoto, H., S. Tagashira, M.-G. Mattei, M. Yamasaki, G. Hashimoto, T. Katsumata, T. Negoro, M. Nakatsuka, D. Birnbaum, F. Coulier, and N. Itoh. 1997. Structure and expression of human fibroblast growth factor-10. J. Biol. Chem. 272: 23191-23194.

Fu, Y-M., P. Spirito, Z-X. Yu, S. Biro, J. Sasse, J. Lei, V.J. Ferrans, S.E. Epstein, and W. Casscells. 1991. Acidic fibroblast growth factor in the developing rat embryo. J. Cell Biol. 114: 1261-1273.

Guo, L., L. Degentstein, and E. Fuchs. 1996. Keratinocyte growth factor is required for hair development but not for wound healing. Genes \& Dev. 10: $165-175$.

Igarashi, M., P.W. Finch, and S.A. Aaronson. 1998. Characterization of recombinant human fibroblast growth factor (FGF)-10 reveals functional similarities with keratinocyte growth factor (FGF-7). J. Biol. Chem. 273: 13230-13235.

Johnson, R.L. and C.J. Tabin. 1997. Molecular models for vertebrate limb development. Cell 90: 979-990.

Kaufman, M.H. 1992. The atlas of mouse development. Academic Press, New York, NY.

Loomis, C.A., E. Harris, J. Michaud, W. Wurst, M. Hanks, and A.L. Joyner. 1996. The mouse Engrailed-1 gene and ventral limb patterning. Nature 382: 360-363.

Lopez-Martinez, A., D.T. Chang, C. Chiang, J.A. Porter, M.A. Ros, B.K. Simandl, P.A. Beachy, and J.F. Fallon. 1995. Limb-patterning activity and restricted posterior localization of the amino-ternimal product of Sonic hedgehog cleavage. Curr. Biol. 5: 791-796.

Martin, G.R. 1998. The roles of FGFs in the early development of vertebrate limbs. Genes \& Dev. 12: 1571-1586.

Mason, I. J., F. Fuller-Pace, R. Smith, and C. Dickson. 1994. Fgf7 (keratinocyte growth factor) expression suggests roles in myogenesis, forebrain regionalisation and epithelial-mesenchymal interactions. Mech. Dev. 45: 15-30.

McKeehan, W.L., F. Wang, and M. Kan. 1998. The heparan sulfate-fibroblast growth factor family: Diversity of structure and function. Prog. Nucleic Acid Res. Mol. Biol. 59: 135-176.

Miller, D. and J.E. Tarpley. 1996 An automated double staining procedure for bone and cartilage. Biotech. Histochem. 71: 79-83.

Nogawa, H. and T. Ito. 1995. Branching morphogenesis of embryonic mouse lung epithelium in mesenchyme-free culture. Development 121: 1015-1022.

Ohuchi, H., T. Nakagawa, M. Yamauchi, T. Ohata, H. Yoshioka, T. Kuwana, T. Mima, T. Mikawa, T. Nohno, and S. Noji. 1995. An additional limb can be induced from the flank of the chick embryo by FGF4. Biochem. Biophys. Res. Commun. 209: 809-816.

Ohuchi, H., T. Nakagawa, A. Yamamoto, A. Araga, T. Ohata, Y. Ishimaru, H. Yoshioka, T. Kuwana, T. Nohno, M. Yamasaki, N. Itoh, and S. Noji. 1997. The mesenchymal factor, FGF10, initiates and maintains the outgrowth of the chick limb bud through interaction with FGF8, an apical ectodermal factor. Development 124: 2235-2244.

Ornitz, D.M., J. Xu, J.S. Colvin, D.G. McEwen, C.A. MacArthur, F. Coulier, G. Gao, and M. Goldfarb. 1996. Receptor specificity of the fibroblast growth factor family. J. Biol. Chem. 271: 15292-15297.

Orr-Urtreger, A., M.T. Bedford, T. Burakova, E. Arman, Y. Zimmer, A. Yayon, D. Givol, and P. Lonai. 1993. Developmental localization of the splicing alternatives of fibroblast growth factor 2 (FGFR2). Dev. Biol. 158: 475-486.
Parr, B.A. and A.P. McMahon. 1995. Dorsalizing signal Wnt-7a required for normal polarity of D-V and A-P axes of mouse limb. Nature 374: $350-353$.

Peters, K., S. Werner, X. Liao, S. Wert, J. Whitsett, and L. Williams. 1994. Targeted expression of a dominant negative FGF receptor blocks branching morphogenesis and epithelial differentiation of the mouse lung. EMBO J. 13: 3296-3301.

Post, M., P. Souza, J. Liu, I. Tseu, J. Wang, M. Kuliszewski, and A.K. Tanswell. 1996. Keratinocyte growth factor and its receptor are involved in regulating early lung branching. Development 122: 31073115.

Riddle, R.D., R.L. Johnson, E. Laufer, and C. Tabin. 1993. Sonic hedgehog mediates the polarizing activity of the ZPA. Cell 75: 1401-1416.

Riddle, R.D., M. Ensini, C. Nelson, T. Tsuchida, T.M. Jessell, and C. Tabin. 1995. Induction of the LIM homeobox gene Lmxl by Wnt 7a establishes dorsoventral pattern in the vertebrate limb. Cell 83: 631640.

Sanford, L.P., I. Ormsby, A.C. Gittenberger-de Groot, H. Sariola, R. Friedman, G.P. Boivin, E.L. Cardell, and T. Doetschman. 1997. TGFß2 knockout mice have multiple developmental defects that are nonoverlapping with other TGF $\beta$ knockout phenotypes. Development 124: 2659-2670.

Saunders, J.W., Jr. 1948. The proximo-distal sequence of the origin of the parts of the chick wing and the role of the ectoderm. J. Exp. Zool. 108: 363-403.

Saunders, J.W. and M.T. Gasseling. 1968. Ectoderm-mesenchymal interactions in the origin of wing symmetry. In Epithelial-mesenchymal interactions (ed. R. Fleischmajer and R.E. Billingham), pp. 78-97. Williams and Wilkins, Baltimore, MD.

Saunders, J.W. Jr. and C. Reuss. 1974. Inductive and axial properties of prospective wing-bud mesoderm in the chick embryo. Dev. Biol 38: $41-50$.

Simonet, W.S., M.L. DeRose, N. Bucay, H.Q. Nguyen, S.E. Wert, L. Zhou, T.R. Ulich, A. Thomason, D.M. Danilenko, and J.A. Whitsett. 1995. Pulmonary malformation in transgenic mice expressing human keratinocyte growth factor in the lung. Proc. Natl. Acad. Sci. 92: 1246112465

Sutherland, D., C. Samakovlis, and M.A. Krasnow. 1996. Branchless en codes a Drosophila FGF homolog that controls tracheal cell migration and the pattern of branching. Cell 87: 1091-1101.

Tagashira, S., H. Harada, T. Katsumata, N. Itoh, and M. Nakatsuka. 1997. Cloning of mouse FGF10 and up-regulation of its gene expression during wound healing. Gene 197: 399-404.

Vogel, A., C. Rodriguez, and J.-C. Izpisúa-Belmonte. 1996. Involvement of FGF-8 in initiation, outgrowth and patterning of the vertebrate limb. Development 122: 1737-1750.

Wert, S., S.W. Glasser, T.R. Korfhagen, and J.A. Whitsett. 1993. Transcriptional elements from the human SP-C gene direct expression in the primordial respiratory epithelium of transgenic mice. Dev. Biol. 156: $426-443$

Wilcox, J.N. 1993. Fundamental principles of in situ hybridization. J. Histochem.Cytochem. 41: 1721-1723.

Xu, X., M. Weinstein, C. Li, M. Naski, R.I. Cohen, D.M. Ornitz, P. Leder, and C. Deng. 1998. Fibroblast growth factor receptor 2 (FGFR2) mediated reciprocal regulation loop between FGF8 and FGF10 is essential for limb induction. Development 125: 767-775.

Yamasaki, M., A. Miyake, S. Tagashira, and N. Itoh. 1996. Structure and expression of the rat mRNA encoding a novel member of the fibroblast growth factor family. J. Biol. Chem. 271: 15918-15921. 


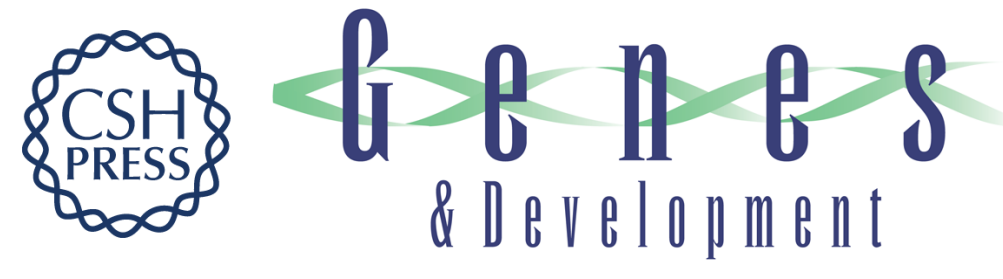

\section{Fgf-10 is required for both limb and lung development and exhibits striking functional similarity to Drosophila branchless}

Hosung Min, Dimitry M. Danilenko, Sheila A. Scully, et al.

Genes Dev. 1998, 12:

Access the most recent version at doi:10.1101/gad.12.20.3156

References

This article cites 38 articles, 16 of which can be accessed free at: http://genesdev.cshlp.org/content/12/20/3156.full.html\#ref-list-1

License

Email Alerting

Receive free email alerts when new articles cite this article - sign up in the box at the top Service right corner of the article or click here.

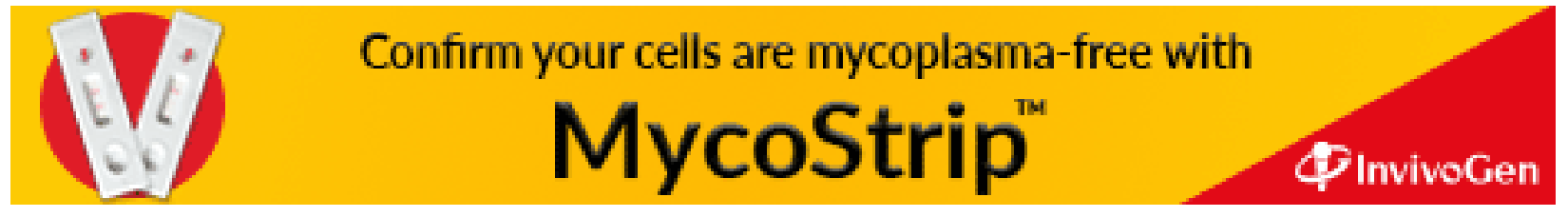

